\title{
PEMANFAATAN NILAI-NILAI FILOSOFIS PUNAKAWAN DALAM UPAYA PENGUATAN KARAKTER MAHASISWA
}

\author{
Ilham Syahrul Jiwandono ${ }^{1}$, Khairunnisa ${ }^{2}$ \\ Universitas Mataram \\ ilham_jiwandono@unram.ac.id ${ }^{1}$, khairunisa.pgsd@gmail.com²
}

\begin{abstract}
ABSTRAK
Perkembangan zaman telah menyebabkan terjadinya degradasi moral yang dialami oleh mahasiswa. Terdapat berbagai indikasi terjadinya degradasi moral di lingkungan kampus. Diperlukan berbagai upaya untuk mengantisipasi permasalahan tersebut. Banyak media yang dapat digunakan untuk menumbuhkan karakter dalam rangka mengatasi permasalahan degradasi moral, baik yang bersifat konvensional maupun modern. Salah satu media konvensional yang dapat dipakai adalah wayang, khususnya Punakawan. Banyak nilai filosofis yang terkandung dalam pertunjukan wayang yang dapat membentuk dan menumbuhkan karakter mahasiswa. Penelitian ini bertujuan untuk mengetahui pemanfaatan media wayang dan nilai-nilai yang terkandung di dalamnya sebagai upaya untuk menumbuhkan karakter mahasiswa. Penelitian ini menggunakan metode kualitatif. Lokasi penelitian di Program Studi Pendidikan Guru Sekolah Dasar Universitas Mataram. Teknik pengambilan data menggunakan wawancara tidak terstruktur, observasi dan dokumentasi. Teknik analisis data menggunakan reduksi data, penyajian data dan penarikan kesimpulan. Hasil penelitian menunjukkan: (1) telah terjadi degradasi moral di lingkungan kampus dengan salah satu bukti hilangnya sopan santun antaran mahasiswa dan dosen. (2) media wayang merupakan media yang sangat cocok untuk membentuk karakter mahasiswa karena banyak nilai yang terkandung di dalamnya. (3) nilai filosofis yang terkandung dalam media wayang.
\end{abstract}

Katakunci: pendidikan karakter, wayang, nilai filosofis

\section{ABSTRACT}

The times have caused moral degradation experienced by students. There are various indications of moral degradation in the campus environment. Various efforts are needed to anticipate these problems. Many media can be used to grow character in order to overcome the problem of moral degradation, both conventional and modern. One of the conventional media that can be used is puppets. Many philosophical values contained in puppet shows can shape and grow student character. This study aims to determine the use of puppet media and the values contained in it as an effort to grow the character of students. This study uses a qualitative method. The location of the study was at the University of Mataram, Elementary School Teacher Education Study Program. Data collection techniques using depth interviews, observation and documentation. Data analysis techniques using data reduction, data presentation and drawing conclusions. The results showed: (1) there has been a moral degradation in the campus environment with evidence of the loss of courtesy between students and lecturers. (2) puppet is a media that is very suitable for shaping student character because of the many values contained. (3) philosophical values contained in puppet, including humility, honesty, discipline and responsibility.

Keywords: character education, puppets, philosophical values

\section{PENDAHULUAN}

Pengalaman sejarah bangsa ini menunjukkan bahwa pendidikan merupakan benih harapan bagi kemajuan, sedangkan pembagunan karakter merupakan roh dari jiwa 
pendidikan dan majunya pembangunan kebangsaan. Dalam pembangunan berkelanjutan, negara harus menempatkan pembangunan generasi muda sebagai prioritas utama dan dalam pembangunan generasi muda hendaknya yang pertama-tama ditekankan adalah pembangunan karakter kebangsaannya.

Presiden Joko Widodo akhirnya membaca situasi ini. Melalui Perpres No 87 tahun 2017 tentang Penguatan Pendidikan Karakter, presiden ingin memperbaiki karakter bangsa yang sedang menurun. Dalam Perpres ini disebutkan, Penguatan Pendidikan Karakter yang selanjutnya disingkat PPK adalah gerakan pendidikan di bawah tanggung jawab satuan pendidikan untuk memperkuat karakter peserta didik melalui harmonisasi olah hati, olah rasa, olah pikir, dan olah raga dengan pelibatan dan kerja sama antara satuan pendidikan, keluarga, dan masyarakat sebagai bagian dari Gerakan Nasional Revolusi Mental (GNRM).

PPK, menurut Perpres ini, memiliki tujuan: (a) membangun dan membekali Peserta Didik sebagai generasi emas Indonesia Tahun 2045 dengan jiwa Pancasila dan pendidikan karakter yang baik guna menghadapi dinamika perubahan di masa depan; (b) mengembangkan platform pendidikan nasional yang meletakkan pendidikan karakter sebagai jiwa utama dalam penyelenggaraan pendidikan bagi Peserta Didik dengan dukungan pelibatan publik yang dilakukan melalui pendidikan jalur formal, nonformal, dan informal dengan memperhatikan keberagaman budaya Indonesia; dan (c) merevitalisasi dan memperkuat potensi dan kompetensi pendidik, tenaga kependidikan, Peserta Didik, masyarakat, dan lingkungan keluarga dalam mengimplementasikan PPK.

Budaya luhur bangsa bisa luntur, identitas bangsa bisa tergeser dan karakter bangsa akan mudah tergerus. Karena itu, pendidikan karakter harus difokuskan pada pembangunan karakter kebangsaan melalui pembangunan pemahaman terhadap pilar-pilar kebangsaan, nilai-nilai sejarah dan kepahlawanan, serta kearifan luhur budaya lokal. Mengenai betapa pentingnya karakter bagi suatu bangsa, Bung Karno pernah berkata "Apa yang menentukan besar kecilnya suatu bangsa? Besar atau kecilnya suatu bangsa bukanlah ditentukan oleh seberapa luas wilayahnya dan seberapa banyak penduduknya, melainkan ditentukan oleh kekuatan tekad sebagai pancaran dari karakternya".

Pendidikan sebagai sumber harapan hendaknya menempatkan pendidikan karakter sebagai tumpuan dasar. Pendidikan yang terlalu mengutamakan aspek kognitif dan lahiriah semata sudah selayaknya mulai kita tinggalkan. 
Apalah artinya nilai A kalau itu hasil mengada-ada atau adakah artinya nilai 90 kalau itu hasil mencontek? Apalah arti cerdas akuntansi dan berdiplomasi kalau nantinya dipakai korupsi? Apalah arti kecerdasan materi dan teori pelajaran kalau salah dalam pemanfaatan? Seseorang dikatakan berkarakter jikatelah berhasil menyerap nilai dan keyakinan(baik) yang dikehendaki masyarakat sertadigunakan sebagai kekuatan moral dalamhidupnya (Prasetyo \& Rivashinta, 2011).

Lebih jauh, Nurgiyantoro (2011) menjelaskan bahwa pendidikan karakter seharusnya menanamkan kebiasaan tentang halhal baik sehingga anak didik dapat memahami (kognitif), mampu merasakan dan membuat pilihan (afektif), dan menerapkan dalam tingkah laku hidup keseharian (psikomotorik). Salah satu media yang tepat dalam mengubah karakter bangsa adalah melalui wayang. Selama ini wayang identik dengan orang-orang yang sudah berumur, namun jika mau memanfaatkan, maka akan menjadi hal yang sangat luar biasa. Tokoh-tokoh dalam pewayangan mempunyai karakter yang beda-beda dan ini cocok untuk menumbuhkan karakter. Bahkan, mantan Menteri Dalam Negeri Tjahjo Kumolo mengatakan pagelaran wayang merupakan salah satu media untuk mensosialisasikan kecintaan terhadap Indonesia dan kebhinekaan yang sudah dimiliki Indonesia sejak lama. Sebab Presiden Joko Widodo juga ingin membangun bangsa tidak secara fisik saja, tapi juga dari moral. Untuk itu perlu diingatkan bahwa membangun karakter sangat penting. Sementara, seorang pemimpin dan pamong harus mampu menggerakkan masyarakat. agar kehidupan berbangsa dan bernegara lebih baik lagi.

Seni wayang terdapat kearifan lokal yang bermanfaat untuk membangun karakter dan jatidiri bangsa Indonesia yang tergambarkan melalui watak tokoh dalam wayang. Indonesia kaya akan berbagai jensi wayang, menurut laporan Sekretarian Pewayangan Indonesia (Senawangi) terdapat 100 jenis wayang yang tersebur di Nusantara. Namun demikian hingga sekarang jenis wayang yang masih hidup dan bertahan di tengah-tengah masyarakat dapat dihitung dengan jari (Kusbiyanto, 2015). Menurut Mubah (2011), Jati diri bangsa sebagai nilai identitas masyarakat harus dibangun secara kokoh dan diinternalisasikan secara mendalam. Caranya, dengan menanamkan nilainilai kearifan lokal sejak dini kepada generasi muda. Harus dipahami, nilai-nilai kearifan lokal bukanlah nilai usang yang ketinggalan zaman sehingga ditinggalkan, tetapi dapat bersinergi dengan nilai-nilai universal dan nilai-nilai modern yang dibawa globalisasi. 


\section{METODE PENELITIAN}

Metode dalam penelitian ini adalah metode kualitatif. Menurut Moleong (2006), metode penelitian kualitatif adalah penelitian yang bermaksud untuk memahami fenomena tentang apa yang dialami oleh subjek penelitian misalnya perilaku, persepsi, motivasi, tindakan, dll secara holistik dan dengan cara deskripsi dalam bentuk kata-kata dan bahasa, pada suatu konteks khusus yang alamiah dan dengan memanfaatkan berbagai metode alamiah. Lokasi penelitian di program Studi Pendidikan Guru Sekolah Dasar Universitas Mataram. Sumber data primer adalah mahasiswa semester 5 Program Studi Pendidikan Guru Sekolah Dasar Universtas Mataram dan sumber data sekunder dari berbagi media massa. Teknik Pengambilan data melalui wawancara tidak terstruktur, observasi dan dokumentasi. Teknik analisis data menggunakan teknik analisis data interaktif dari Miles \& Huberman (1992) yang meliputi tahap reduksi data, penyajian data, dan penarikan simpulan.

\section{HASIL PENELITIAN DAN}

\section{PEMBAHASAN}

\section{Rendahnya Karakter Mahasiswa}

Penulis sebagai dosen PPKn di kampus mempunyai tanggung jawab yang besar dalam rangka meningkatkan karakter mahasiswa. Apalagi melihat karakter mahasiswa di tempat penulis mengajar saat ini.
Dari hasil observasi di lokasi penelitian, penulis menemukan berbagai indikasi penuruan karakter mahasiswa, diantaranya adalah semakin tingginya individualisme dan apatisme terhadap keadaan sekitar. Hasil observasi ini didukung oleh hasil wawancara dengan mahasiswa yang menjelaskan bahwa saat ini banyak mahasiswa yang apatis terhadap keadaan sekitar, salah satu yang mereka soroti adalah masalah kebersihan di kampus dimana banyak sampah berserakan. Menurutnya, mahasiswa lebih perhatian kepada dirinya sendiri ketimbang lingkungan sekitar. Hal ini sejalan dengan pendapat Rahayu (2007) yang mengatakan bahwa mahasiswa lebih perhatian kepada dirinya dan keluarganya dibandingkan dengan masyarakat sekitar. Selain itu, sopan santun juga menjadi masalah serius yang harus segera dipecahkan.

Hasil observasi menunjukkan bahwa selama ini di lokasi penelitian, sopan santun mahasiswa perlu ditingkatkan lagi. Baik itu tingkah laku maupun tutur katanya. Keduanya tidak bisa dipisahkan. Hal ini sejalan dengan pernyataan Suwadji (1985) bahwa sopan santun atau unggah-ungguh berbahasa dalam bahasa Jawa mencakup dua hal, yaitu tingkah laku atau sikap berbahasa penutur dan wujud tuturannya, atau dapat disebut sebagai patrap dan pangucap (Suharti, 1993) Sampai hari ini permasalahan tersebut semakin 
menggurita. Berbagai persoalan tersebut tentunya mempunyai dampak yang sangat serius apabila tidak segera dipecahkan. Dampakdampak yang bisa terjadi diantaranya: (1) Menurunnya Rasa Hormat Terhadap Dosen, (2) Semakin tingginya angka kenakalan mahasiswa. (3) Tindak pidana oleh mahasiswa. Hal ini sesuai dengan hasil wawancara dengan mahasiswa yang menyebutkan bahwa saat ini banyak mahasiswa yang tersangkut masalah pidana, salah satunya adalah pencurian. Wawancara tersebut juga diperkuat oleh dokumentasi yang penulis lakukan terhadap salah satu media nasional yang menyebutkan bahwa sepanjang tahun 2018 terdapat 392 kasus 3C di Kota Mataram (Hernawardi, 2018). Oleh karena itu bangsa kita perlu mempesiapkan diri dengan karakter bangsa yang relevan. Untuk menciptakan karakter bangsa yang relevan, pendidikan sebagai wadah reproduksi kompetensi bangsa adalah salah satu resolusi yang dianggap paling strategis.

\section{Penggalian Wayang Sebagai Media Menumbuhkan \\ Karakter Mahasiswa.}

Anggoro (2018) dalam jurnalnya mengatakan bahwa Salah satu bentuk kesenian yang berkembang di Indonesia adalah pergelaran wayang kulit. Dimana salah satu bentuk kebudayaan dari wayang dilambangkan dengan tokoh punakawan. Hal senada juga diungkapkan oleh Nurgiyantoro (2011) yang mengatakan bahwa Di Indonesia, khususnya Jawa, mitologi wayang merupakan tradisi dan budaya yang telah mendasari dan berperan besar dalam membentuk karakter dan eksistensi bangsa Indonesia. Hal itu disebabkan mitologi merupakan kristalisasi konsep-konsep, nilai-nilai, dan norma-norma yang menjiwai sikap hidup masyarakat selama ini dan menyebabkan komunikasi antaranggota masyarakat menjadi efisien.

Berdasarkan penjelasan diatas, maka diperlukan suatu media yang dapat merangsang keaktifan siswa di dalam kelas. Penjelasan tersebut cocok dengan penggunaan media wayang sebagai upaya untuk membangkitkan kesadaran dan keinginan mahasiswa untuk memperbaiki merosotnya karakter bangsa. Berdasar hasil wawancara dengan mahasiswa, pertunjukan wayang sangat cocok dipakai dalam rangka menumbuhkan karakter, karena di dalam pertunjukan wayang terdapat banyak tokoh beserta karakter yang dibawanya. Hal ini sejalan dengan pendapat Santosa (2011:39) yang mengatakan bahwa tujuan utama pertunjukan wayang adalah memberikan petunjuk kepada manusia untuk berlaku yang baik dan benar dan memacu cipta, rasa, dan karsa ikut membangun bebrayan 
agung, serta memayu hayuning bawana.

Pertunjukan wayang memiliki budi pekerti luhur yang diharapkan membuat kehidupan masyarakat berada dalam kerangka tata tentrem kertaraharja. Pesan moral menjadi sangat dominan dalam wayang, termasuk ajaran mengenal dan menyadari sangkan paraning dumadi atau asal mula kehidupan. Disamping itu, wayang memberikan hiburan yang sehat bagi para penontonnya. Ada unsur-unsur tragedi, komedi, dan tragikomedi (Kominfo, 2011). Dalam pelaksanaanya, Guru dapat sebagai sutradara yang bertugas mengkoordinasi lalu lintas pertunjukan wayang agar berhasil (Rinurbad, 2009).

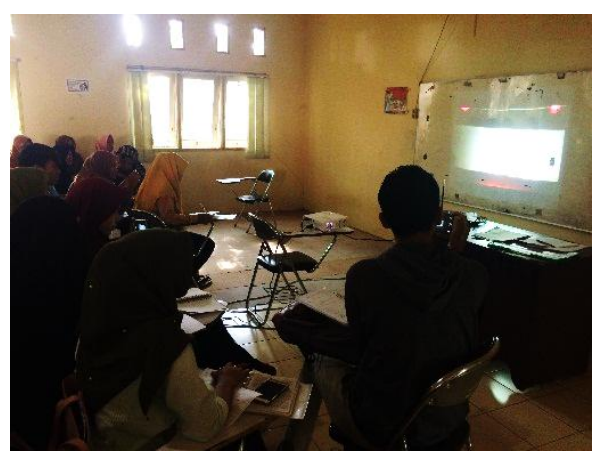

Gambar 1. Mahasiswa mengamati pertunjukan wayang

Permasalahan saat ini adalah Nilai pendidikan budi pekerti dalam pertunjukan wayang akhir-akhir ini menjadi luntur karena hanya menafsirkan muatan budi pekerti dalam ucapan dalang, tetapi tidak utuh dalam keseluruhan pertunjukan wayang. Hal ini karena pertunjukan wayang telah bergeser dari makna ritual menjadi sebuah hiburan. Pendapat penulis sejalan dengan apa yang dikatakan oleh (Sutarso dan Mulyanto, 2008) yang menjelaskan bahwa dalang sekarang sering berbicara porno dan humor vulgar dan tidak sesuai dengan pakem dalang.

Pemanfaatan wayang sebagai sarana pembelajaran bagi anak kini telah menjadi alternatif yang efektif dalam menyampaikan pesan pendidikan karakter.Segala bentuk visualisasi yang telah dipaparkan dalam kisah-kisah wayang dapat memberikan gambaran sifat-sifat, watak serta perilaku sosial manusia di kehidupan dimana ada yang baik dan ada yang buruk.

\section{Nilai-Nilai Filosofis Pada Punakawan}

Pada pertunjukan wayang, umumnya kita mengenal berbagai tokoh yang membawa karakter masing-masing. Pertunjukan wayang kulit dapat digunakan dalam pembinaan moral, menyampaikan pesan-pesan tertentu yang mendidik, dan dapat memotivasi semangat kemasyarakatan (Purwanto, 2018). Berdasar hasil wawancara dengan mahasiswa, diketahui bahwa ada beberapa tokoh wayang yang karakternya cocok untuk diterapkan di kalangan mahasiswa, misalnya semar yang rendah hati dan jujur. Hal ini sejalan dengan apa yang ditulis oleh Kresna (2002) yang menjelaskan ada beberapa tokoh dalam 
pewayangan yang filosofinya sangat dibutuhkan hingga kini, diantaranya: (1) Semar. dengan jari telunjuk seolah menuding, melambangkan karsa/keinginan yang kuat untuk menciptakan sesuatu. Mata yang menyipit juga melambangkan ketelitian dan keseriusandalam menciptakan. (2) Gareng. anak pertama Semar, dengan tangan yang cacat, kaki yang pinang, mata yang juling, melambangkan cipta, bahwa menciptakan sesuatu, dan tidak sempurna. Kita tidak boleh menyerah, bagaimanapun kita sudah berusaha.Apapun hasilnya, pasrahkan padaNya. (3) Petruk. Dengan tangan dan kaki yang panjang, tubuh tinggi langsing, hidung mancung, wujud dari cipta, yang kemudian diberi rasa, sehingga terlihat lebih indah dengan begitu banyak kelebihan. (4) Bagong. Walau Petruk lengkap dengan keindahan dan kesempurnaan, tapi Bagong lah yang dianggap sebagai manusia yang utuh. Karena dia memiliki kekurangan. Jadi jangan takut atau malu karena kekurangan kita. Karena kekurangan itulah yang menjadikan kita manusia seutuhnya.

\section{SIMPULAN}

Dari uraian di atas dapat ditarik kesimpulan sebagai berikut:

1. Lingkungan kampus sebagai lingkungan akademik seyogyanya mencerminkan susasana akademik yang bagus, namun hal itu sedikit ternoda akibat banyaknya mahasiswa yang melanggar kaidah-kaidah yang telah disetujui.

2. Penurunan karakter yang dialami oleh mahasiswa benar adanya dengan bukti banyaknya pelanggaran-pelanggaran yang mahasiswa lakukan di lingkungan kampus.

3. Wayang merupakan media konvensional yang digunakan dalam proses pembelajaran di kelas. Banyak nilai-nilai filosofis yang terkandung dalam pewayangan. Nilai-nilai tersebut bisa diambil dan diinternalisasikan ke dalam diri mahasiswa.

\section{DAFTAR PUSTAKA}

Anggoro, Bayu. 2018. Wayang dan Seni Pertunjukan: Kajian Sejarah Perkembangan Seni Wayang di Tanah Jawa sebagai Seni Pertunjukan dan Dakwah. JUSPI: Jurnal Sejarah Peradaban Islam, Vol. 2 No. 2

Hernawardi. 2018. Angka Kejahatan Meningkat di Kota Mataram Tahun 2018. (online). (https://www.gatra.com/detail /news/376594-AngkaKejahatan-Meningkat-di-KotaMataram-Tahun-2018). Diakses 10 januari 2019

Kementerian Komunikasi dan Informatika RI, Direktorat Jendral Informasi dan Komunikasi Publik. 2011. Wayang Sebagai Media Komunikasi Tradisional Dalam Diseminasi Informasi. Jakarta: 
Kementerian Komunikasi dan Informatika RI.

Kresna, Ardian. 2002. Punakawan. Yogyakarta: Penerbit Narasi

Kusbiyanto, Mari. 2015. Upaya Mencegah Hilangnya Wayang Kulit Sebagai Ekspresi Budaya Warisan Budaya Bangsa Jurnal Hukum dan Pembangunan, Vol. 45 , No. 4

Miles, M.B., \& Huberman, A.M. 1992.Analisis Data Kualitatif, Buku Sumber tentang Metodemetode Baru. Jakarta: UI Press

Moleong, Lexy. 2006. Metodologi Penelitian Kualitatif. Bandung: PT. Remaja Rosdakarya.

Mubah, A. Safril. Strategi Meningkatkan Daya Daya Tahan Budaya Lokal dalam Menghadapi Arus Globalisasi. Vol. 24, No. 4. Surabaya: Fisip Univ. Airlangga.

Nurgiyantoro, Burhan. 2011. Wayang Dan Pengembangan Karakter Bangsa. Jurnal Pendidikan Karakter, Vol. 1, No. 1

Prasetyo, A. \& Rivashinta, E. 2011. Konsep Urgensi dan Implementasi Pendidikan Karakter di Sekolah. (online).(http://edukasi.kompa siana.com,). Diakses tanggal 27 Mei 2019.

Purwanto, Sigit. 2018. Pendidikan Nilai Dalam Pagelaran Wayang Kulit. TA'ALLUM: Jurnal Pendidikan Islam Vol. 6, No. 1

Rahayu, Minto. 2007. Bahasa Indonesia di Perguruan Tinggi Mata Kuliah Pengembangan Kepribadian. Jakarta: Grasindo
Rinurbad. 2009. Ayo Bermain Teater. Cirebon: CV. Gunung Djati

Santosa, Imam Budhi. 2011. Saripati Ajaran Hidup Dahsyat dari Jagad Wayang. Jogjakarta: Flashbook

Suharti, dkk. 1993. Kajian Unggahungguh Bahasa Jawa dalam Keluarga Jawa di Yogyakarta. Yogyakarta : Pusat Penelitian IKIP Yogyakarta

Sutarso, J \& Mulyoto, B. 2008. Wayang Sebagai Sumber dan Materi Pembelajaran Pendidikan Budi Pekerti Berbasis Budaya Lokal. Jurnal Penelitian Humaniora, Vol. 9, No. 1

Suwadji. 1985. Sopan Santun Berbahasa dalan Bahasa Jawa. Widyaparwa. Yogyakarta : Balai Penelitian Bahasa. 